\title{
IDENTIFIKASI KENYAMANAN PEJALAN KAKI DI CITY WALK JALAN SLAMET RIYADI SURAKARTA
}

\author{
Kuncoro Harsono, Yayi Arsandrie, Wisnu Setiawan \\ Program Studi Teknik Arsitektur, Fakultas Teknik, Universitas Muhammadiyah Surakarta \\ Jl. A. Yani Tromol Pos 1 Pabelan Kartasura Sukoharjo 57102 Telp 0271-717417 \\ E-mail: kuncoroharsono@yahoo.com
}

\begin{abstract}
ABSTRAK
Pedestrian adalah jalur bagi para pejalan kaki ataupun kursi roda bagi kelompok pengguna berkebutuhan khusus, yang dirancang berdasarkan kebutuhan orang untuk bergerak aman, nyaman dan tak terhalang, termasuk jalur City Walk di Jalan Slamet Riyadi Surakarta. Penelitian ini bermaksud mengkaji ulang apakah City Walk di Jalan Slamet Riyadi Surakarta sudah memenuhi standar kenyamanan bagi penggunanya, termasuk penyandang cacat dan lansia, serta standar aksesibilitas pada fasilitasfasilitasnya. Penelitian ini mencoba mengidentifikasi faktor kenyamanan yang ada di City Walk. Metode penelitian yang digunakan adalah metode deskriptif dengan mengemukakan fakta-fakta yang ada di lapangan, kemudian dibandingkan dengan standar aksesibilitas. Hasil riset menunjukkan bahwa secara umum jalur City Walk di Jalan Slamet Riyadi Surakarta memiliki fasilitas-fasilitas utama yang sudah memenuhi standar, seperti lebar pedestrian, kondisi tempat duduk dan vegetasi. Hanya terdapat kekurangan pada kondisi kebersihan dan ketersediaan rambu-rambu bagi kelompok pengguna berkebutuhan khusus. Gangguan terbesar yang dirasakan pengguna bersumber dari keberadaan parkir liar dan Pedagang Kaki Lima (PKL).
\end{abstract}

Kata Kunci: City Walk, kenyamanan, pedestrian

\section{PENDAHULUAN}

Pedestrian adalah jalur bagi para pejalan kaki ataupun pengguna kursi roda bagi kelompok berkebutuhan khusus, yang dirancang berdasarkan kebutuhan orang untuk bergerak aman, nyaman dan tak terhalang. Sebagai contoh, Surakarta memiliki kawasan City Walk yang membentang di Jalan Slamet Riyadi sampai Gladak. Ruas jalan tersebut merupakan salah satu pusat perekonomian yang sangat padat di Surakarta, dengan toko-toko yang sangat ramai. Untuk memberi kenyamanan bagi pengunjung ataupun pembeli agar merasa nyaman, kawasan ini menyediakan jalur pedestrian yang kemudian dikenal sebagai kawasan City Walk.

Hasil pengamatan awal menunjukkan bahwa pedestrian di kawasan City Walk saat ini sudah beralih fungsi dan memiliki kondisi yang sangat mengkhawatirkan. Hal ini memberikan indikasi bahwa permasalahan kualitas pedestrian di City Walk Jalan Slamet Riyadi berkaitan dengan kesesuaian fasilitas yang ada dengan standar yang berlaku. Permasalahan penelitian dapat dirumuskan sebagai berikut:

1. Bagaimana tingkat kenyamanan pedestrian di City Walk Jalan Slamet Riyadi Surakarta?

2. Bagaimana tingkat kesesuaian pedestrian di City Walk Jalan Slamet Riyadi dengan standar yang berlaku?

Adapun tujuan dilakukannya penelitian ini adalah sebagai berikut:

1. Untuk mengetahui tingkat kenyamanan pengunjung yang menggunakan City Walk sebagai jalur pedestrian.

2. Untuk memberikan rekomendasi terhadap pengembangan City Walk di Jalan Slamet Riyadi Surakarta sebagai jalur pedestrian yang memenuhi standar kenyamanan.

Penelitian ini menggunakan metode penelitian dengan pendekatan deskriptif kualitatif, dimana peneliti mengumpulkan kelengkapan data literatur dan data lapangan. Selanjutnya, data yang ada dibandingkan 
dengan standar yang diperoleh dari hasil kajian literatur.

Hasil analisis ini akan menunjukkan kesesuaian fasilitas pedestrian yang ada terhadap standar aksesibilitas yang berlaku.

\section{KAJIAN PUSTAKA Pedestrian}

Pedestrian berasal dari bahasa Yunani pedos yang berarti kaki. Pedestrian dapat diartikan sebagai pejalan kaki atau orang yang berjalan kaki (Salmanisaleh, 2011). Pedestrian dapat pula secara umum disebut sebagai fasilitas bagi orang yang bepergian atau melakukan perjalanan dengan berjalan kaki ataupun dengan cara lari (Iswanto, 2006).

Berkaitan dengan fungsinya untuk dapat melayani seluruh lapisan masyarakat, pedestrian juga dipahami sebagai jalur bagi para pejalan kaki ataupun pengguna kursi roda yang dirancang berdasarkan kebutuhan orang untuk bergerak aman, nyaman dan tak terhalang (Peraturan Menteri Pekerjaan Umum No. 30/PRT/M/2006).

\section{Fasilitas Jalur Pedestrian}

Menurut Salmanisaleh (2011), terdapat 2 macam fasilitas pedestrian, yaitu fasilitas pedestrian yang terlindung dan fasilitas pedestrian yang tidak terlindung/terbuka.

1. Fasilitas pedestrian yang terlindung di dalam bangunan, meliputi 2 macam jalur pedestrian: (1) jalur pedestrian vertikal (seperti tangga dan ramp) dan (2) jalur pedestrian horizontal (seperti koridor dan hall).

2. Fasilitas pedestrian yang terlindung di luar bangunan, meliputi 4 macam pedestrian: (1) Arcade, yaitu selasar yang terbentuk oleh sederetan kolom-kolom, biasanya merupakan bagian luar dari bangunan atau dapat juga berdiri sendiri; (2) Gallery, yaitu lorong yang lebar, umumnya terdapat pada lantai teratas; (3) Covered Walk atau selasar, yaitu fasilitas pedestrian yang pada umumnya terdapat di rumah sakit atau asrama atau bangunan yang lainnya; serta (4) Shopping mall, merupakan fasilitas pedestrian yang sangat luas yang biasanya terletak di dalam bangunan perbelanjaan.

3. Fasilitas pedestrian yang tidak terlindung / terbuka meliputi beberapa contoh berikut (1) Trotoir / sidewalk, yaitu fasilitas jalur pedestrian dengan lantai perkerasan, (2) Foot path / jalan setapak, yaitu fasilitas jalur pedestrian seperti gang di lingkungan permukiman kampung, (3) Plaza, yaitu tempat terbuka dengan lantai perkerasan, berfungsi sebagai pengikat massa bangunan, (4) Pedestrian mall, yaitu jalur pedestrian yang cukup luas, yang digunakan untuk sirkulasi pejalan kaki atau interaksi sosial, (5) Zebra cross, yaitu fasilitas jalur pedestrian untuk menyeberang di jalan.

\section{Persyaratan Teknis Jalur Pedestrian}

Menurut Salmanisaleh (2011), beberapa persyaratan teknis jalur pedestrian yang perlu diperhatikan adalah sebagai berikut :

1. Mudah dan jelas: fasilitas pedestrian yang dibuat harus mudah diakses.

2. Nyaman dan aman: fasilitas pedestrian harus dirancang sesuai dengan standar yang berlaku baik dari bentuk ataupun kontruksinya.

3. Permukaan: permukaan harus stabil, kuat, tahan cuaca, halus namun tidak licin.

4. Kemiringan: kemiringan melintang 2-3\% agar tidak ada genangan air, kemiringan memanjang maksimal $7 \%$.

5. Area istirahat: disarankan agar terdapat tempat duduk untuk pemberhentian/ istirahat terutama bagi pengguna kaum difable.

6. Lebar: berdasarkan kebutuhan orang,lebar efektif minimum ruang pejalan kaki adalah $60 \mathrm{~cm}$ ditambah $15 \mathrm{~cm}$ untuk bergoyang tanpa membawa barang; sehingga kebutuhan total 2 orang pejalan kaki berpapasan tanpa terjadi persinggungan adalah $150 \mathrm{~cm}$.

\section{Elemen Material Jalur Pedestrian}

Elemen-elemen material yang umumnya digunakan pada jalur pedestrian adalah paving (beton), batu atau bata.

1. Paving/beton: dibuat dengan tekstur, warna, dan variasi bentuk yang memiliki kelebihan dapat terlihat seperti batu bata, serta pemasangan dan pemeliharaannya mudah.

2. Batu: merupakan salah satu material yang paling tahan lama, memiliki daya tahan yang kuat dan mudah dalam pemeliharaannya. 
3. Bata: bahan material ini mudah pemeliharaannya, serta mudah pula didapat. Bata memiliki tekstur dan dapat menyerap air dan panas dengan cepat tetapi mudah retak.

\section{Tipologi Ruang Pejalan Kaki}

Menurut Peraturan Menteri Pekerjaan Umum No. 30/PRT/M/2006 terdapat beberapa tipologi ruang pejalan kaki, seperti ditunjukkan pada Gambar 1.

Menurut Badan Standardisasi Nasional (2000), beberapa elemen ruang pejalan kaki yang umum ditemukan meliputi antara lain:

1. Drainase, berfungsi sebagai penampung dan jalur aliran air pada ruang pejalan kaki.

2. Jalur hijau, biasanya diletakkan pada jalur potensial.
3. Lampu penerangan pada umumnya diletakkan pada jalur potensial.

4. Tempat duduk diletakkan pada jalur potensial.

5. Pagar pengaman diletakkan pada titik tertentu yang berbahaya dan memerlukan perlindungan.

6. Tempat sampah diletakkan di jalur potensial.

7. Marka dan perambuan, papan informasi (signage) diletakkan pada jalur potensial.

8. Halte/shelter bus dan lapak tunggu diletakkan pada jalur potensial.

8. Telepon umum terletak pada setiap radius 300 meter.

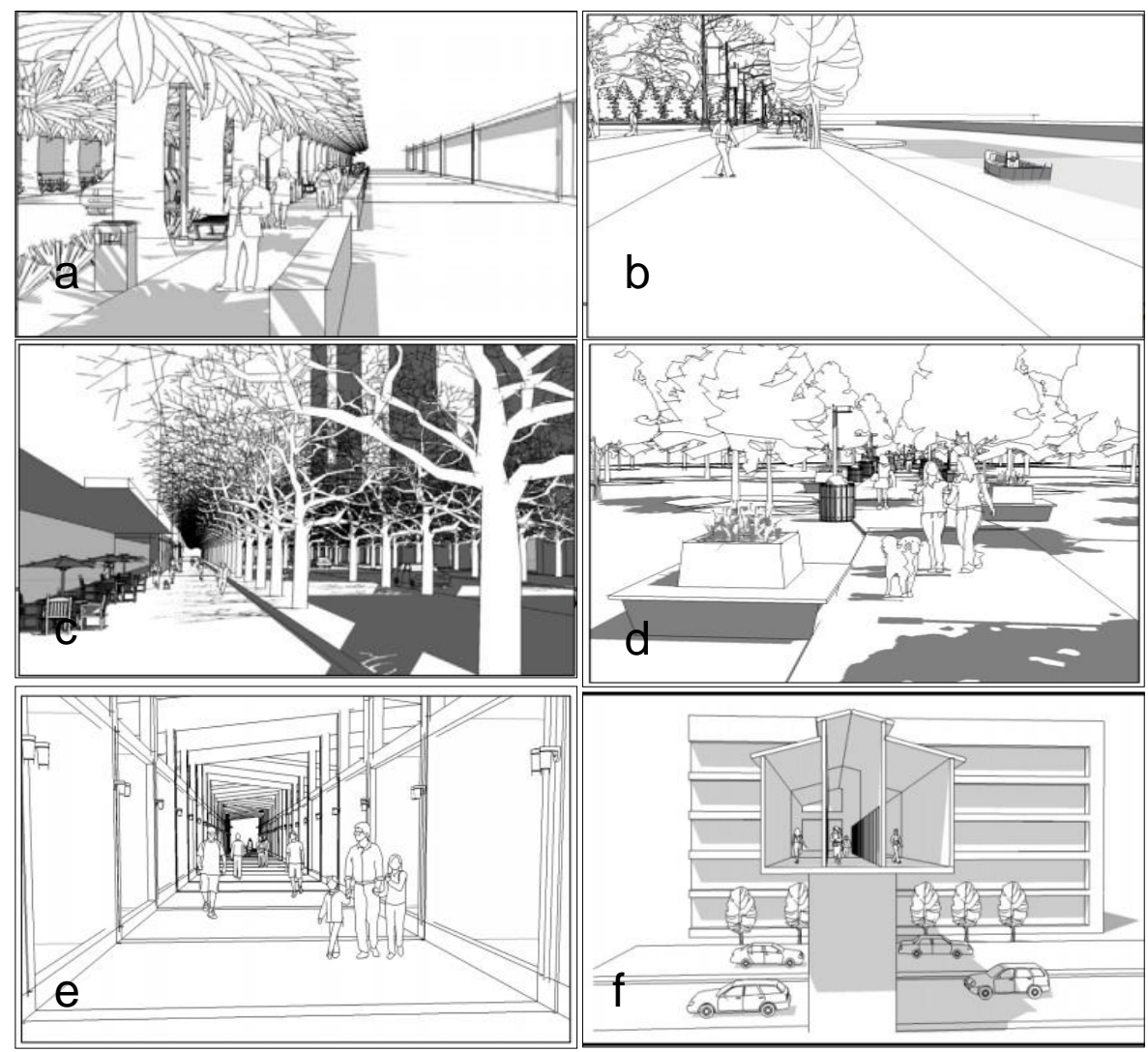

Gambar 1. Contoh Tipologi Ruang Pejalan Kaki

(Sumber: Peraturan Menteri PU, 2006)

Keterangan: (a) ruang pejalan kaki di sisi jalan (sidewalk); (b) ruang pejalan kaki di sisi air (promenade); (c) ruang pejalan kaki di kawasan komersial/perkantoran (arcade);

(d) ruang pejalan kaki di RTH (green pathway); (e) ruang pejalan kaki di bawah tanah (underground); (f) ruang pejalan kaki di atas tanah (elevated) 


\section{Aksesibilitas}

Dalam kaitannya dengan desain pedestrian, aksesibilitas diperlukan untuk memberikan kemudahan bagi semua orang termasuk pengguna berkebutuhan khusus, seperti kelompok difabel dan lansia guna mewujudkan kesamaan kesempatan dalam aspek kehidupan dan penghidupan. Bambang Sutantono (2004). menyatakan bahwa aksesibilitas adalah "hak atas akses yang merupakan layanan kebutuhan untuk melakukan perjalanan yang mendasar". Dalam hal ini aksesibilitas harus disediakan oleh pemerintah terlepas dari digunakannya moda transportasi yang disediakan tersebut oleh masyarakat. Aksesibilitas merupakan konsep pedestrian yang disediakan untuk semua orang termasuk kelompok difabel dan lansia, dengan tujuan mendapatkan kenyamanan bagi penggunanya.

\section{Asas Fasilitas dan Aksesibilitas}

Dalam memberikan fasilitas dan aksesibilitas ada 4 asas yang perlu diperhatikan (Komnaslansia, 2010), yaitu:

1. Keselamatan: setiap bangunan yang bersifat umum harus memperhatikan keselamatan bagi semua orang.

2. Kemudahan: setiap orang dapat mencapai semua tempat atau bangunan.

3. Kegunaan: setiap orang harus dapat mempergunakan semua tempat atau bangunan.

4. Kemandirian: setiap orang harus bisa mencapai, masuk dan mempergunakan semua tempat atau bangunan yang bersifat umum.

\section{Fasilitas Difable}

Menurut Peraturan Menteri Pekerjaan

Umum No. 30/PRT/M/2006, persyaratan khusus untuk rancangan bagi pejalan kaki yang mempunyai keterbatasan fisik adalah sebagai berikut:

1. Jalan tersebut setidaknya memiliki lebar 1,5 meter, dengan tingkat kemiringan maksimal $5 \%$.

2. Pejalan kaki harus mudah mengenal permukaan jalan yang lurus atau perubahan jalan yang curam pada tingkat tertentu.
3. Menghindari berbagai bahaya yang berpotensi mengancam keselamatan.

4. Ketika pengguna berkebutuhan khusus menyeberang jalan, tingkat trotoarnya harus disesuaikan.

5. Berbagai perubahan dalam tekstur trotoar dapat digunakan sebagai tanda-tanda praktis.

6. Jalan tersebut tidak boleh memiliki permukaan yang licin.

Tipe fasilitas difabel adalah:

1. Ram (ramp), diletakkan di setiap persimpangan, entrance bangunan, dan pada titik-titik penyeberangan.

2. Jalur difabel, diletakkan di sepanjang prasarana jaringan pejalan kaki.

\section{METODE PENELITIAN \\ Lokasi Penelitian}

Penelitian ini mengambil beberapa titik pengamatan dengan pertimbangan bahwa di titik tersebut terdapat banyak aktivitas pedestrian (Gambar 2 dan 3).

1. Titik pengamatan 1: Terletak di depan Solo Grand Mall,

2. Titik pengamatan 2 : Terletak di depan Taman Sriwedari,

3. Titik pengamatan 3 terletak di depan BCA (Bank Central Asia). Di titik ini terdapat banyak orang yang lalu lalang, karena terletak di dekat PGS (Pusat Grosir Solo). 


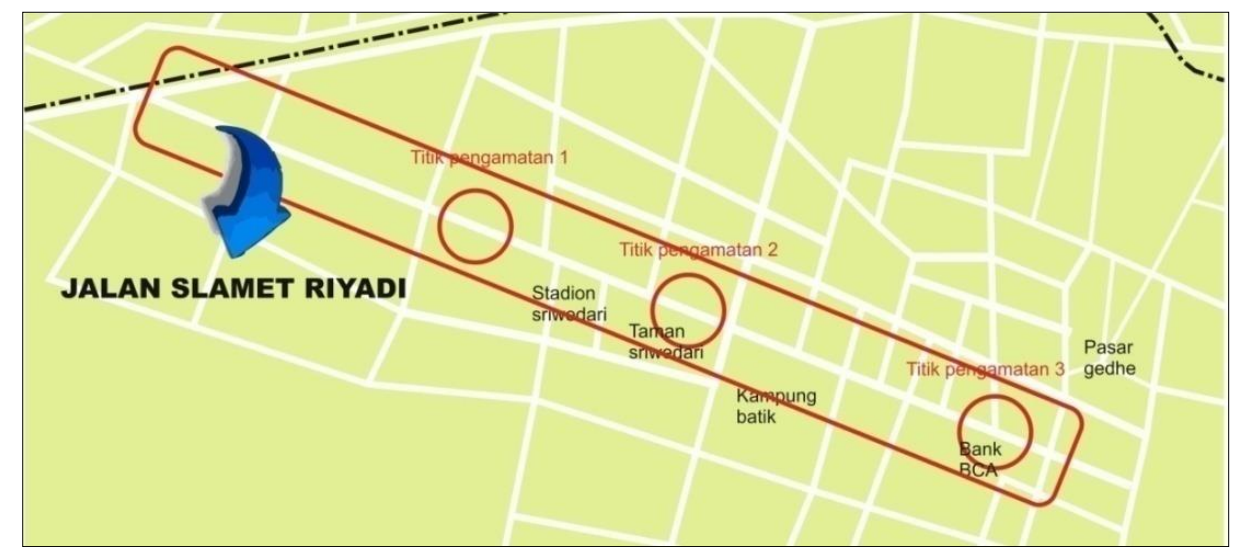

Gambar 2. Lokasi pengamatan 3 titik pengamatan di Jalan Slamet Riyadi, Surakarta (Sumber: Survei, 2014)

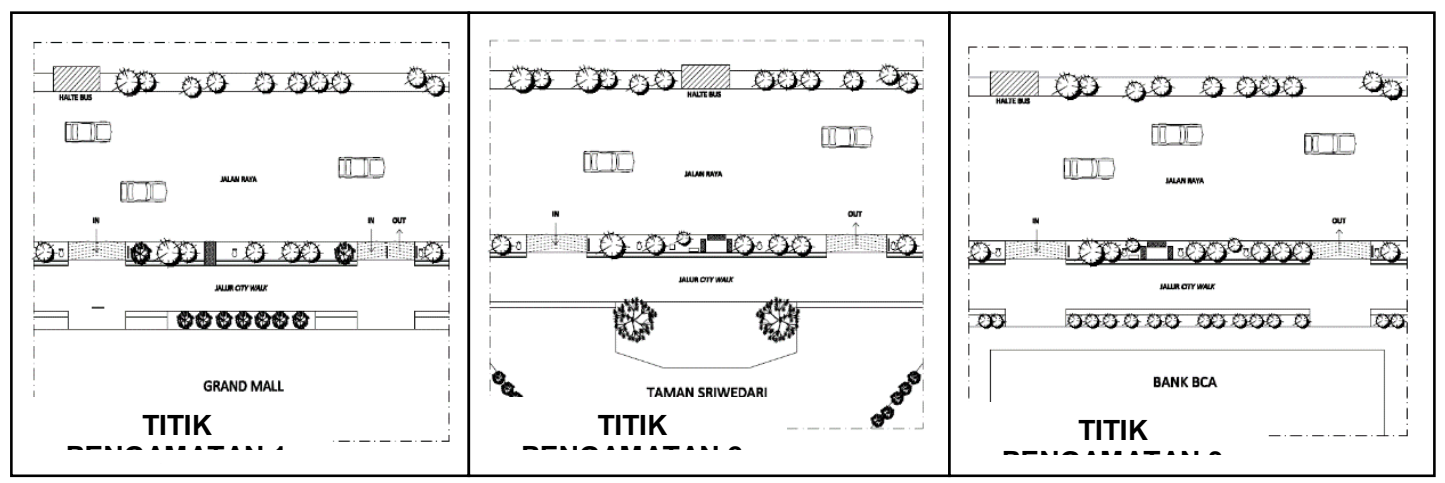

Gambar 3. Gambar detail situasi di 3 titik pengamatandi Jalan Slamet Riyadi, Surakarta

(Sumber: Survei, 2014)

\section{Elemen Pengamatan}

Beberapa elemen yang menjadi sasaran pengamatan ditampilkan dalam Tabel 1 berikut ini:

Tabel 1. Elemen dan Parameter Pengamatan

\begin{tabular}{|c|l|l|}
\hline No & Elemen & \multicolumn{1}{|c|}{ Parameter } \\
\hline 1. & Drainase & $\begin{array}{l}\text { Lebar } \\
\text { Kedalaman }\end{array}$ \\
\hline 2. & Jalur hijau & $\begin{array}{l}\text { Tanaman peneduh } \\
\text { Jenis/karakter tanaman }\end{array}$ \\
\hline 3. & $\begin{array}{l}\text { Lampu } \\
\text { penerangan }\end{array}$ & $\begin{array}{l}\text { Ketinggian } \\
\text { Jarak antar lampu } \\
\text { Material yang digunakan }\end{array}$ \\
\hline 4. & $\begin{array}{l}\text { Tempat } \\
\text { duduk }\end{array}$ & $\begin{array}{l}\text { Ketinggian } \\
\text { Panjang } \\
\text { Lebar } \\
\text { Penempatan }\end{array}$ \\
\hline 5. & $\begin{array}{l}\text { Pagar } \\
\text { pengaman }\end{array}$ & $\begin{array}{l}\text { Ketinggian } \\
\text { Material yang digunakan } \\
\text { Penempatan }\end{array}$ \\
\hline 6. & $\begin{array}{l}\text { Tempat } \\
\text { sampah }\end{array}$ & $\begin{array}{l}\text { Penempatan } \\
\text { Material yang digunakan }\end{array}$ \\
\hline 7. & $\begin{array}{l}\text { Marka, } \\
\text { perambuan, } \\
\text { papan } \\
\text { informasi }\end{array}$ & $\begin{array}{l}\text { Penempatan } \\
\text { Material yang digunakan } \\
\text { Kejelasan informasi }\end{array}$ \\
\hline
\end{tabular}

\begin{tabular}{|c|l|l|}
\hline 8. & $\begin{array}{l}\text { Halte/shelter } \\
\text { bus dan } \\
\text { lapak tunggu }\end{array}$ & $\begin{array}{l}\text { Penempatan } \\
\text { Kenyamanan } \\
\text { keamanan } \\
\text { Kapasitas }\end{array}$ \\
\hline 9. & $\begin{array}{l}\text { Telepon } \\
\text { umum }\end{array}$ & $\begin{array}{l}\text { Penempatan } \\
\text { Material yang digunakan }\end{array}$ \\
\hline 10. & $\begin{array}{l}\text { Fasilitas } \\
\text { bagi difabel }\end{array}$ & $\begin{array}{l}\text { Penempatan } \\
\text { Material yang digunakan } \\
\text { Jenis fasilitas } \\
\text { Kesesuaian standar }\end{array}$ \\
\hline 11. & $\begin{array}{l}\text { Material jalur } \\
\text { pedestrian }\end{array}$ & Material yang digunakan \\
\hline
\end{tabular}

Sumber: Survei, 2014

\section{HASIL DAN PEMBAHASAN \\ Hasil pengamatan lapangan}

Secara umum, suasana di 3 titik pengamatan ditunjukkan oleh Gambar 2. Sedangkan hasil pengamatan di 3 titik tersebut dikelompokkan menjadi beberapa bagian, sesuai dengan persyaratan pedestrian yang terdapat di literatur. Lebih rinci, Tabel 1 menjelaskan bagaimana kesesuaian antara pengamatan lapangan tersebut terhadap persyaratan yang ada. 
Hasil penelitian di 3 titik pengamatan menunjukkan beberapa fenomena, antara lain sebagai berikut:

1. Drainase

Secara umum, drainase yang terdapat di 3 lokasi amatan City Walk Jalan Slamet Riyadi belum memenuhi standar lebar drainase minimal $50 \mathrm{~cm}$ dan kedalaman 50 $\mathrm{cm}$. Tetapi, sebagian drainase yang terdapat di 3 titik pengamatan terlihat bersih.

2. Jalur hijau

Jalur hijau yang terdapat di 3 lokasi amatan City Walk Jalan Slamet Riyadi sudah memenuhi standar dan diletakkan pada jalur potensial.

3. Lampu penerangan

Lampu penerangan yang terdapat di titik pengamatan 2 dan 3 City Walk Jalan Slamet Riyadi sudah memenuhi standar dengan tinggi lampu penerangan maksimal adalah 4 meter dan jarak 10 meter. Hanya di titik pengamatan 1 tidak memenuhi standar.

4. Tempat duduk

Tempat duduk yang terdapat di 3 lokasi amatan City Walk Jalan Slamet Riyadi sudah memenuhi standar lebar tempat duduk 40-50 cm dan panjang $150 \mathrm{~cm}$. Namun, penempatan tempat duduk kurang maksimal dan tidak memenuhi standar.

5. Pagar pengaman

Tidak terdapat pagar pengaman di 3 lokasi amatan City Walk Jalan Slamet Riyadi.

6. Tempat sampah

Tempat sampah yang terdapat di 3 lokasi amatan City Walk Jalan Slamet Riyadi tidak memenuhi standar lebar $100 \mathrm{~cm}$ dan penempatan di setiap jarak 20 meter. Berdasarkan hasil pengamatan di lapangan, penempatan tempat sampah kurang maksimal, banyak yang berlubang dan tidak terawat.

7. Marka, perambuan, papan informasi

Secara umum, marka, perambuan, papan informasi yang terdapat di 3 lokasi amatan City Walk Jalan Slamet Riyadi sudah memenuhi standar sesuai dengan persyaratan, dimana material yang digunakan tidak menyilaukan pengguna jalan. Namun untuk perambuan kaum difabel dan lansia tidak ada.

8. Halte bus
Halte bus yang terdapat di 3 lokasi amatan City Walk Jalan Slamet Riyadi sudah memenuhi persyaratan, yaitu diletakkan pada jalur potensial. Hanya saja, kebersihan di sekitar halte bus masih kurang.

9. Telepon umum

Kondisi telepon umum tidak memenuhi standar: telepon umum di titik pengamatan 2 sudah tidak dipakai lagi dan di titik pengamatan 1 dan 3 tidak ada telepon umum.

10 Fasilitas kaum difabel

Tidak terdapat fasilitas kaum difabel di 3 lokasi amatan City Walk Jalan Slamet Riyadi.

11. Material pedestrian

Material pedestrian yang terdapat di 3 lokasi amatan City Walk Jalan Slamet Riyadi sudah memenuhi standar: material yang digunakan adalah beton, paving, batu, dan bata. Namun, jalur pedestrian khusus untuk kaum difabel di 3 titik pengamatan belum ada. 
Tabel 2. Hasil Pengamatan di 3 Titik Pengamatan

\begin{tabular}{|c|c|c|c|c|c|c|}
\hline No & Elemen & Pengamatan & \multicolumn{3}{|c|}{ Lokasi } & Keterangan \\
\hline \multirow{2}{*}{1.} & \multirow{2}{*}{ Drainase } & \multirow{2}{*}{ Kedalaman } & $25 \mathrm{~cm}$ & $25 \mathrm{~cm}$ & $25 \mathrm{~cm}$ & \multirow{2}{*}{$\begin{array}{l}\text { Tidak } \\
\text { sesuai }\end{array}$} \\
\hline & & & $30 \mathrm{~cm}$ & $30 \mathrm{~cm}$ & $30 \mathrm{~cm}$ & \\
\hline \multirow[t]{2}{*}{2.} & \multirow[t]{2}{*}{ Jalur hijau } & Nama tanaman & $\begin{array}{c}\text { Pohon pinus } \\
\text { Pohon talok } \\
\text { Pohon } \\
\text { beringin }\end{array}$ & $\begin{array}{l}\text { Pohon } \\
\text { beringin } \\
\text { Pohon } \\
\text { mahoni }\end{array}$ & $\begin{array}{l}\text { Pohon } \\
\text { mahoni }\end{array}$ & \multirow[t]{2}{*}{ Sesuai } \\
\hline & & $\begin{array}{l}\text { Jenis dan } \\
\text { karakter }\end{array}$ & Peneduh & Peneduh & Peneduh & \\
\hline \multirow{3}{*}{3.} & \multirow{3}{*}{$\begin{array}{l}\text { Lampu } \\
\text { penerangan }\end{array}$} & Ketinggian & $5 \mathrm{~m}$ & $4 \mathrm{~m}$ & $4 \mathrm{~m}$ dan $5 \mathrm{~m}$ & \multirow{3}{*}{ Sesuai } \\
\hline & & Jarak antar lampu & $20 \mathrm{~m}$ & $10 \mathrm{~m}$ & $\begin{array}{c}10 \mathrm{~m} \text { dan } 20 \\
\mathrm{~m}\end{array}$ & \\
\hline & & Material & Besi dan seng & $\begin{array}{l}\text { Besi dan } \\
\text { seng }\end{array}$ & $\begin{array}{l}\text { Besi dan } \\
\text { seng }\end{array}$ & \\
\hline \multirow{4}{*}{4.} & \multirow{4}{*}{ Tempat duduk } & Ketinggian & - & $45 \mathrm{~cm}$ & $45 \mathrm{~cm}$ & \multirow{4}{*}{ Sesuai } \\
\hline & & Panjang & - & $\begin{array}{c}1 \mathrm{~m} \text { dan } 1,5 \\
\mathrm{~m}\end{array}$ & $\begin{array}{c}1 \mathrm{~m} \text { dan } 1,5 \\
\mathrm{~m}\end{array}$ & \\
\hline & & Lebar & - & $40 \mathrm{~cm}$ & $40 \mathrm{~cm}$ & \\
\hline & & Penempatan & - & Sesuai & Sesuai & \\
\hline \multirow{3}{*}{5.} & \multirow{3}{*}{$\begin{array}{l}\text { Pagar } \\
\text { pengaman }\end{array}$} & Ketinggian & - & - & - & \multirow{3}{*}{$\begin{array}{l}\text { Tidak } \\
\text { sesuai }\end{array}$} \\
\hline & & Material & - & - & - & \\
\hline & & Penempatan & - & - & - & \\
\hline \multirow[b]{2}{*}{6.} & \multirow[b]{2}{*}{ Tempat sampah } & Penempatan & - & Tidak sesuai & Tidak sesuai & \multirow[b]{2}{*}{$\begin{array}{l}\text { Tidak } \\
\text { sesuai }\end{array}$} \\
\hline & & Material & - & Besi dan kayu & $\begin{array}{l}\text { Besi dan } \\
\text { kayu }\end{array}$ & \\
\hline \multirow{3}{*}{7.} & \multirow{3}{*}{$\begin{array}{l}\text { Marka, } \\
\text { perambuan, } \\
\text { papan informasi }\end{array}$} & Penempatan & Sesuai & Sesuai & Sesuai & \multirow{3}{*}{ Sesuai } \\
\hline & & Material & Besi dan seng & $\begin{array}{c}\text { Besi dan } \\
\text { seng }\end{array}$ & $\begin{array}{c}\text { Besi dan } \\
\text { seng }\end{array}$ & \\
\hline & & $\begin{array}{l}\text { Kejelasan } \\
\text { informasi }\end{array}$ & Jelas & Jelas & Jelas & \\
\hline \multirow[b]{4}{*}{8.} & \multirow[b]{4}{*}{ Halte bus } & Penempatan & Sesuai & Sesuai & Sesuai & \multirow[b]{4}{*}{ Sesuai } \\
\hline & & Kenyamanan & Nyaman & Nyaman & Nyaman & \\
\hline & & Kapasitas & 10 orang & 10 orang & 10 orang & \\
\hline & & Material & $\begin{array}{l}\text { Besi, seng, } \\
\text { kaca, genteng, } \\
\text { dan cor beton }\end{array}$ & $\begin{array}{l}\text { Besi, seng, } \\
\text { policarbonat, } \\
\text { dan cor beton }\end{array}$ & $\begin{array}{l}\text { Besi, seng, } \\
\text { kaca, } \\
\text { genteng, dan } \\
\text { cor beton }\end{array}$ & \\
\hline \multirow{2}{*}{9.} & \multirow{2}{*}{ Telepon umum } & Penempatan & - & Tidak sesuai & & \multirow{2}{*}{$\begin{array}{l}\text { Tidak } \\
\text { sesuai }\end{array}$} \\
\hline & & Material & - & Besi dan fiber & - & \\
\hline & & Penempatan & - & - & - & \\
\hline & & Jenis fasilitas & - & - & - & \\
\hline 10. & Fasilitas difable & Material & - & - & - & IIdak \\
\hline & & $\begin{array}{l}\text { Kesesuaian } \\
\text { standar }\end{array}$ & - & - & - & sesual \\
\hline & & Beton & - & $\checkmark$ & - & \\
\hline 11. & Material & Paving & $\checkmark$ & $\checkmark$ & $\checkmark$ & Sesuai \\
\hline & & Batu bata & - & - & - & \\
\hline
\end{tabular}

Sumber: Survei, 2014 
Hasil Data Questioner

Tabel 3. Jawaban dari Responden

\begin{tabular}{|c|c|c|c|c|c|}
\hline \multirow{2}{*}{ No } & \multirow{2}{*}{$\begin{array}{l}\text { Pertanyaan Questioner } \\
\text { kepada Pengguna Jalan }\end{array}$} & \multicolumn{3}{|c|}{ Jawaban } & \multirow[b]{2}{*}{ Jumlah } \\
\hline & & $\mathbf{A}$ & $\mathbf{B}$ & $\mathbf{C}$ & \\
\hline 1 & $\begin{array}{l}\text { Apakah Anda merasa nyaman berjalan di jalur } \\
\text { pedestrian ini? }\end{array}$ & 20 & 22 & 8 & 50 \\
\hline 2 & $\begin{array}{l}\text { Apakah Anda terganggu dengan para PKL yang } \\
\text { menjajakan dagangannya di area pedestrian ini? }\end{array}$ & 35 & 15 & 0 & 50 \\
\hline 3 & $\begin{array}{l}\text { Apakah Anda merasa nyaman ketika berpapasan } \\
\text { dengan orang lain dengan ukuran jalur pedestrian } \\
\text { sebesar ini? }\end{array}$ & 22 & 25 & 3 & 50 \\
\hline 4 & Apakah vegetasi di pedestrian ini sudah cukup? & 30 & 16 & 4 & 50 \\
\hline 5 & $\begin{array}{l}\text { Apakah menurut Anda perlu disediakan ramp/turunan } \\
\text { untuk kelompok difable? }\end{array}$ & 32 & 12 & 6 & 50 \\
\hline 6 & $\begin{array}{l}\text { Bagaimana tanggapan Anda mengenai kebersihan di } \\
\text { pedestrian ini? Kotor/bersih? }\end{array}$ & 18 & 22 & 10 & 50 \\
\hline 7 & $\begin{array}{l}\text { Apakah Anda merasa panas bila berjalan di pedestrian } \\
\text { ini? }\end{array}$ & 2 & 13 & 35 & 50 \\
\hline 8 & $\begin{array}{l}\text { Apakah dengan penerangan yang ada saat ini Anda } \\
\text { sudah merasa nyaman ketika berjalan kaki di malam } \\
\text { hari di pedestrian ini? }\end{array}$ & 20 & 12 & 18 & 50 \\
\hline 9 & Apakah sudah cukup tempat duduk untuk istirahat? & 8 & 10 & 32 & 5 \\
\hline 10 & Apakah sudah cukup tempat sampah yang disediakan? & 3 & 7 & 40 & 50 \\
\hline 11 & Apakah perlu dibuatkan guiding block untuk tuna netra? & 18 & 22 & 10 & 50 \\
\hline 12 & Apakah sudah cukup kapasitas halte bus? & 17 & 28 & 5 & 50 \\
\hline 13 & $\begin{array}{l}\text { Apakah perlu disediakan penutup untuk menghindari } \\
\text { panas dan hujan? }\end{array}$ & 25 & 23 & 2 & 50 \\
\hline 14 & $\begin{array}{l}\text { Apakah perlu disediakan pot-pot bunga untuk } \\
\text { menambah keindahan pedestrian? }\end{array}$ & 14 & 27 & 9 & 50 \\
\hline 15 & $\begin{array}{l}\text { Apakah parkir kendaraan bermotor di jalur pedestrian } \\
\text { menggangu Anda? }\end{array}$ & 35 & 15 & 0 & 50 \\
\hline 16 & $\begin{array}{l}\text { Apakah terdapat peran serta pemerintah untuk } \\
\text { mengatasi permasalahan pedestrian? }\end{array}$ & 18 & 27 & 5 & 50 \\
\hline & Jumlah $=$ & 316 & 300 & 184 & 800 \\
\hline & Prosentase $=$ & $39,5 \%$ & $37,5 \%$ & $23,0 \%$ & $100 \%$ \\
\hline
\end{tabular}

Keterangan: $\mathbf{A}=$ sangat setuju, $\mathbf{B}=$ setuju, $\mathbf{C}=$ tidak setuju

Sumber: Survei, 2014

\section{Diskusi Hasil Questioner}

Jawaban yang diberikan oleh 50 responden terhadap 16 pertanyaan yang disebar menunjukkan beberapa poin penting berikut ini:

1. Kenyamanan pedestrian sudah cukup dirasakan oleh pengguna; sejumlah $84 \%$ responden merasa nyaman saat berjalan kaki di City Walk dan 94\% responden berpendapat bahwa lebar pedestrian cukup nyaman untuk berjalan.

2. Sejumlah besar responden menyatakan bahwa vegetasi yang tersedia di pedestrian sudah cukup dan responden tidak merasakan panas saat berjalan di siang hari. Namun demikian, sejumlah $96 \%$ responden menginginkan perlindungan ditingkatkan untuk memberikan penutup dari kondisi panas dan hujan.

3. Fasilitas penerangan sudah cukup menciptakan kenyamanan untuk berjalan pada malam hari (64\% responden).

4. Gangguan yang terdapat di jalur City Walk ditimbulkan dari keberadaan Pedagang Kaki Lima (PKL) dan parkir kendaraan bermotor (100\% responden).

5. Sebagian besar pengguna pedestrian menyatakan perlunya disediakan fasilitas ramp dan guiding block untuk kemudahan aksesibilitas bagi kelompok difabel.

6. Sejumlah $80 \%$ pengguna pedestrian menyatakan bahwa kebersihan jalur City 
Walk sudah cukup, namun ketersediaan tempat sampah dirasakan masih kurang.

7. Sejumlah $64 \%$ responden mengatakan bahwa fasilitas tempat istirahat yang disediakan di jalur pedestrian masih kurang, dan sebagian besar setuju untuk penambahan pot-pot bunga untuk memperindah lingkungan pedestrian.

8. Saat ini halte bus yang terdapat di jalur pedestrian City Walk Jalan Slamet Riyadi sudah cukup untuk memfasilitasi sebagian besar pengguna jalur pedestrian.

9. Peran pemerintah sangat penting untuk meningkatkan kenyamanan City Walk. Walaupun sebagian besar jalur pedestrian di Jalan Slamet Riyadi sudah memenuhi standar, ada bagian-bagian yang harus direnovasi ulang untuk membuat jalur pedestrian City Walk lebih baik di masa depan.

\section{KESIMPULAN}

Hasil penelitian menunjukkan bahwa secara umum masyarakat merasa bahwa fasilitas City Walk sudah cukup nyaman untuk berjalan kaki: lebar pedestrian dan vegetasi di jalur pedestrian sudah cukup sehingga pengguna tidak merasa kepanasan pada siang hari. Demikian pula fasilitas penerangan yang cukup membuat pengguna merasa nyaman ketika berjalan pada malam hari. Fasilitas jalur hijau di City Walk Jalan Slamet Riyadi sudah memenuhi standar. Kondisi ini akan menjadi semakin baik jika jalur hijau diberi penutup terutama di lokasi tempat duduk dan diberi pot bunga agar pengguna dapat menikmati udara segar dan keindahan suasana di pedestrian. Hal-hal yang membuat pengguna jalur pedestrian tidak merasa nyaman disebabkan karena perilaku pengguna kendaraan dalam memarkir kendaraan di jalur pedestrian, perilaku pedagang yang memenuhi area pejalan kaki, dan perilaku masyarakat sekitar City Walk Slamet Riyadi yang membuang sampah sembarangan.

\section{Rekomendasi}

Survey yang dilakukan pada penelitian ini mengungkapkan bahwa tingkat kenyamanan pengguna City Walk Jalan Slamet Riyadi sudah cukup baik. Namun, akan lebih baik jika penelitian ini dilakukan di seluruh jalur pedestrian di Surakarta untuk dapat mengetahui secara maksimal tingkat kenyamanan pengguna pedestrian di sepanjang jalur tersebut.

Hasil penelitian terhadap penggunaan jalur pedestrian di City Walk di Jalan Slamet Riyadi harus menjadi pertimbangan pemerintah daerah Surakarta untuk mentertibkan kembali parkir kendaraan dan para PKL (Pedagang Kaki Lima) yang menggunakan jalur pedestrian secara liar. Perbaikan juga harus dilakukan untuk merenovasi fasilitas bagi kaum difabel, seperti ramp, rambu-rambu penunjuk arah, dan penggunaan material sehingga diharapkan pengguna difabel juga dapat menikmati City Walk di sepanjang Jalan Slamet Riyadi Surakarta

\section{DAFTAR PUSTAKA}

Iswanto, D., 2006, Pengaruh Elemen Elemen Pelengkap Jalur Pedestrian terhadap Kenyamanan Pejalan Kaki [online]. Semarang: undip.ac.id. http://eprints.undip.ac.id/18474

Komnaslansia, 2010, Aksesibilitas dan Kemudahan dalam Penggunaan Sarana dan Prasarana Bagi Lanjut Usia [online]. Jakarta: komnaslansia.go.id.

http://www.komnaslansia.go.id/d0wnloads/Aksesibilitas.pdf

Badan Standardisasi Nasional, 2000, Elemen-elemen Ruang Pejalan Kaki [online]. Jakarta: blogspot.com. http://cahyageo.blogspot.com/2012/04/aksesibilitas.html

Peraturan Menteri Pekerjaan Umum No. 30/PRT/M/2006 tentang PedomanTeknis Fasilitas dan Aksesibilitas pada Bangunan Gedung dan Lingkungan 
Salmanisaleh, 2011, Jalur Pejalan Kaki [online]. Jakarta: wordpress.com.

http://salmanisaleh.files.wordpress.com/2011/10/3-jalur-pejalan-kaki.pdf

Sutantono, B., 2004, Accessibility [online]. Jakarta: blogspot.com.

http://cahyageo.blogspot.com/2012/04/aksesibilitas.html 